\title{
THE EFFECTS OF VARYING WATER INTAKE AND OF OTHER MEASURES ON THE RELATIVE SATURATION OF STONE- FORMING SALTS IN THE URINE OF SPINAL CORD PATIENTS
}

\author{
By I. Nuseibeh, F.R.C.S. and R. G. BuRR, M.R.I.C. \\ National Spinal Injuries Centre, Stoke Mandeville Hospital, \\ Aylesbury, Bucks, England
}

Abstract. In our attempts to prevent or treat urinary calculi, we recommend that the patients should force fluids.

This work was undertaken to determine whether it is possible by dilution to maintain the urine of paraplegic patients in a condition of undersaturation with stone-forming salts and, if so, what level of urinary output per 24 hours is necessary.

The subjects studied were 17 spinal cord patients and two control subjects. They all attempted to vary their fluid intake to give a wide range of 24 -hour urine volumes. After analysis, the relative saturation (RS) of the urine with respect to the relevant salts was obtained from the Marshall-Robertson nomograms modified to take account of changes in ionic strength. The 24-hour volumes required to reduce RS to zero were found to be $\mathrm{I} \cdot 3$ to IO.I litres for brushite, $0 \cdot 3$ to $8 \cdot 3$ for octocalcium phosphate and 0 to I 9 litres for magnesium ammonium phosphate.

A nomogram was constructed to permit calculation of the 24 -hour volume required to maintain urinary under-saturation after measurement of calcium, of phosphate and of $\mathrm{pH}$. The use of this nomogram will facilitate assessment of whether dilution therapy is likely to be helpful in the treatment of stone disease in any particular case and whether it will do so in the face of the high alkalinity usually encountered in infected urine. We have compared the effects of hard water and soft water and attempted also to calculate what level of $\mathrm{NaCl}$ intake would be needed to achieve the same effect.

Key words: Paraplegia; Urinary calculi.

\section{Patients and Methods}

SEVENTEEN ambulent spinal cord patients and two non-paraplegic patients as control subjects were studied. Twelve of the patients had a history of urinary stones, the remaining five did not. The subjects were encouraged to vary their fluid intake so that a wide range of 24 -hour urine volumes was obtained. The variation in fluid intake was achieved by altering the quantity of cold water ingested, either as tap water or as softened water. The quantity of boiled tap water, taken in the form of either tea or coffee, remained relatively constant. No instructions were given regarding other components of the diet. Beer was regarded as equivalent to tap water.

The period of study, which depended on the patients' co-operation, was from 8 to 27 days (mean 14.7 days). Three patients received tap water only, the rest alternating periods of tap water and softened water. Five subjects received ammonium benzoate $900 \mathrm{mg}$ t.d.s. for $2-4$ days and another patient received ascorbic acid $\mathrm{I} .5 \mathrm{~g}$ t.d.s. for 6 days. The tap water contained $2.5 \mathrm{mmol} \mathrm{Ca}$ per litre, $0.1 \mathrm{mmol} \mathrm{Mg}$ per litre and less than I mmol per litre each of $\mathrm{Na}$ and $\mathrm{K}$. Softened water, obtained by passing water from the tap through a Permutit Model $\mathrm{P}_{4}$ domestic water softener, contained 5-8 mmol Na per litre and less than I mmol K, $0.1 \mathrm{mmol} \mathrm{Ca}$ and $0.05 \mathrm{mmol} \mathrm{Mg}$ per litre. 
Twenty-four-hour urine collections were made using hibitane (20 per cent chlorhexidine gluconate) as preservative ( $5 \mathrm{ml}$ per litre of urine). After $\mathrm{pH}$ measurement by glass electrode, the urine was acidified with $\mathrm{HNO}_{3}$. Sodium and potassium were determined by flame photometry, chloride by Volhard titration, calcium, phosphate, ammonium and creatinine by automated spectrophotometry and magnesium by automated fluorimetry.

For each salt RS $=0$ at the solubility product and RS $=\mathrm{I}$ at the formation product (Marshall \& Robertson, 1976). This means that when RS is greater than I, spontaneous precipitation can occur, even in the absence of a nidus. At RS values below $O$, the urine is under-saturated and any crystals present will tend to dissolve. A value between $O$ and I indicates that new crystals will form in the presence of a nidus such as catheter balloon, dead bacteria, etc., and that preexisting crystals will tend to grow.

The relative saturation of the urine samples with respect to brushite (calcium hydrogen phosphate, referred to below as B), octacalcium phosphate (OCP) and magnesium ammonium phosphate (MAP) were obtained from the nomograms of Marshall and Robertson (1976). The values were corrected for changes in ionic strength as follows. Single ion activity coefficients for $\mathrm{Ca}^{++}, \mathrm{Mg}^{++}, \mathrm{H}^{+}, \mathrm{HPO}_{4}^{--}$ and $\mathrm{PO}_{4}^{---}$were obtained from the data of Conway (1952), Kohn and Furda (1967) and Bates, Staples and Robinson (1970). The corrections to be applied to relative urinary saturation, RS (where RS is the relative saturation as defined by Marshall \& Robinson, 1976), were obtained from the following relations:

B:

$$
\mathrm{RS}=-\log _{10}\left[\begin{array}{c}
\mathrm{f}_{\mathrm{Ca}^{++}}^{\mu} \cdot \mathrm{f}_{\mathrm{HPO}_{4}^{--}}^{\mu} \\
\mathrm{f}_{\mathrm{Ca}^{++}=0 \cdot 15}^{\mu=\mathrm{f}_{\mathrm{HPO}_{4}^{-}}^{\mu}=0 \cdot 15}
\end{array}\right]
$$

where $\mathrm{f}$ is the single ion activity coefficient at ionic strength $\mu$.

OCP:

$$
\mathrm{RS}=-\frac{1}{3} \log _{10}\left[\frac{\left(\mathrm{f}_{\mathrm{Ca}^{++}}^{\mu}\right)^{4} \cdot \mathrm{f}_{\mathrm{H}^{+}}^{\mu} \cdot\left(\mathrm{f}_{\mathrm{PO}_{4}^{--}}^{\mu}\right)^{3}}{\left(\mathrm{f}_{\mathrm{Ca}^{++}+15}^{\mu=0 \cdot 15}\right)^{4} \cdot \mathrm{f}_{\mathrm{H}^{+}}^{\mu=0 \cdot 15} \cdot\left(\mathrm{f}_{\mathrm{PO}_{4}^{-}}^{\mu=0 \cdot 15}\right)^{3}}\right]
$$

MAP:

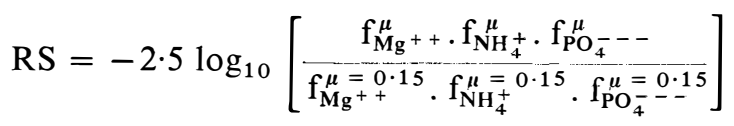

\section{Results}

Table I gives the volumes for which $\mathrm{RS}=\mathrm{o}$ for the ten patients and two control subjects for whom the regression of RS on 24-hour volume of urine was statistically significant. Seven patients were not able to vary their fluid intake sufficiently to yield a significant correlation between RS and volume.. The RS zero volumes were highest for $\mathrm{B}$, for which they ranged from $\mathrm{I} \cdot 27$ to $\mathrm{IO}^{\circ} \mathrm{I} 4$ litres.

Figure I shows the results from a control subject where the regression lines indicate that the urine was under-saturated with $B$ when the 24 -hour volume was over 5.4 litres and with OCP at volumes above 3.7 litres. Ammonium benzoate therapy resulted in a reduction in these values. The urine was under-saturated with MAP at all volumes.

Figure 2 is a nomogram which enables the $\mathrm{RS}_{\mathrm{B}}=0$ volume to be obtained for any patient from measurement of urinary calcium $\times$ phosphate product and $\mathrm{pH}$. It was derived from the Marshall / Robertson nomogram with a correction for ionic 


\section{TABLE I}

Twenty-four-hour volumes below which the urine is under-saturated. Values obtained from the regression lines when $\mathrm{P}<0.05$

\begin{tabular}{|c|c|c|c|c|}
\hline \multicolumn{2}{|r|}{ Patient } & \multirow[t]{2}{*}{ Brushite } & \multirow{2}{*}{$\begin{array}{l}\text { Octacalcium } \\
\text { phosphate }\end{array}$} & \multirow{2}{*}{$\begin{array}{l}\text { Magnesium } \\
\text { ammonium } \\
\text { phosphate }\end{array}$} \\
\hline Sex & Stone disease & & & \\
\hline $\mathrm{F}$ & + & $\mathrm{I} \cdot 27 \mathrm{l}$ & ns & ns \\
\hline $\mathrm{F}$ & + & $2 \cdot 191$ & $2 \cdot 2$ I 1 & ${ }^{\star} \mathrm{I} \cdot \mathrm{I}_{4} 1$ \\
\hline$M$ & - & $2 \cdot 191$ & 0.271 & - \\
\hline$M$ & - & $\star_{2} .521$ & $I \cdot 231$ & ns \\
\hline$M$ & + & $\star \star 2 \cdot 921$ & $\star_{2} .561$ & ${ }^{\star \star}$ I I9 1 \\
\hline$M$ & + & $\star^{\star} 3.9 \mathrm{I} 1$ & ns & ns \\
\hline$M$ & + & 4.821 & 3.921 & $\mathrm{I} \cdot 781$ \\
\hline$M$ & + & $\star \star 5.821$ & $\star \star 5.651$ & ${ }^{\star} \mathrm{I} \cdot 471$ \\
\hline $\mathrm{F}$ & - & $\star_{7} .061$ & $\star 6.261$ & I $\cdot 941$ \\
\hline$M$ & + & IO.I4 1 & $8 \cdot 341$ & ns \\
\hline \multicolumn{5}{|c|}{ Healthy subjects } \\
\hline $\mathrm{F}$ & - & ${ }^{\star} 7.93 \mathrm{I}$ & $7 \cdot 201$ & $-12 \cdot 851$ \\
\hline$M$ & - & $\star \star 5.381$ & $\star_{3}^{\prime} .731$ & $\star \star-3.291$ \\
\hline
\end{tabular}

strength based on the relationship between ionic strength and 24 -hour volume obtained from our patient data (228 samples).

In no patient did ingestion of softened water significantly alter the relationship between RS and volume. The results obtained were similar to those shown for one patient in Fig. 3. The effect of ammonium benzoate administration was also negligible in the patients on whom they were tested.

The attempt was made to assess the feasibility of increasing solubility by increasing urinary ionic strength. The quantity of sodium chloride which would need to be added to each urine specimen to depress its RS value to zero was calculated. A typical result is shown in Fig. 4. The amount required was frequently far in excess of the maximum acceptable daily intake of sodium chloride (Wade, I977).

\section{Discussion}

Dilution of urine is frequently recommended for the stone-forming patient by virtue of its effect on urinary infection as well as on salt concentrations (Thomas, I974).

The principal crystalline components of urinary calculi from paraplegic patients are calcium phosphate (in one or more of its forms) and magnesium ammonium phosphate (Burr, I978). For a calculus to form, urine must regularly become over-saturated with respect to these salts. There is reason to expect that if the urine could at all times be kept under-saturated, stone growth would not occur (Clark \& Nordin, I969; Finlayson, 1974).

For the above-mentioned salts, the state of saturation of a sample of urine 


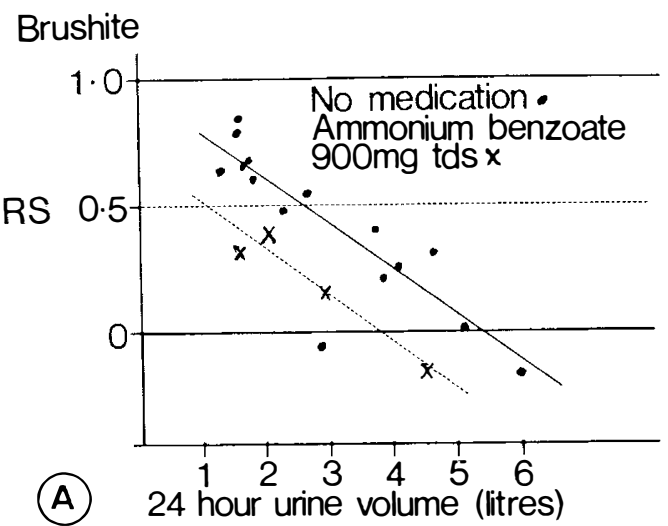

Octocalcium phosphate

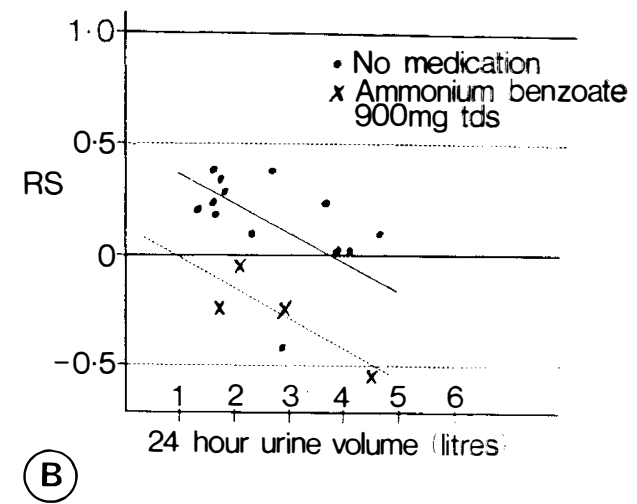

Magnesium ammonium phosphate

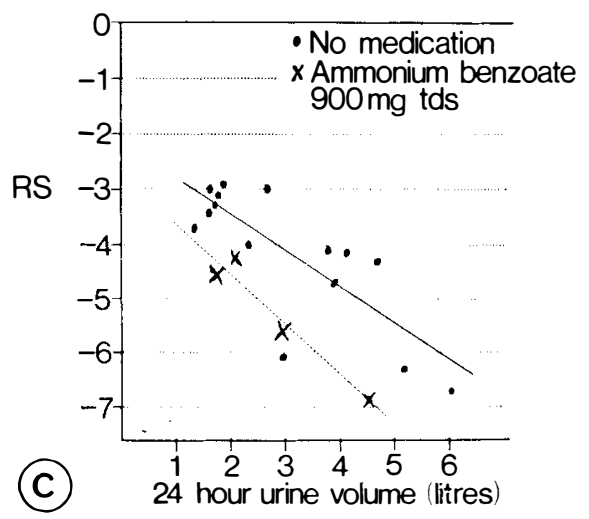

FIG. I

Results from a healthy non-paraplegic male subject. Regression of RS (relative saturation) on Volume for $(a)$ brushite (calcium hydrogen phosphate), $(b)$ octocalcium phosphate, $(c)$ magnesium ammonium phosphate. Results obtained during ammonium benzoate administration are included for comparison.

depends on its $\mathrm{pH}$, the concentrations of calcium, magnesium, ammonium and phosphate, and on its ionic strength (determined chiefly by the sodium, potassium and chloride concentrations). Under-saturation may in theory be brought about by one or a combination of the following: lowering the $\mathrm{pH}$, reducing the urinary excretion of calcium, magnesium and phosphate, by dilution, or by increasing the excretion of sodium, potassium and chloride. Attention in the past has been focussed primarily on the $\mathrm{pH}$, which is quantitatively the most important factor. In practice, however, acidification of the urine is often not easily achieved owing to the presence of infection by urease-positive organisms.

In our experience, reduction of phosphate excretion, which can be brought about by means of alumina gel therapy, is not effective in the long term due perhaps to the difficulties experienced by the patients in continuing with the huge dosage of the medication or due to concomitant rise in urinary $\mathrm{pH}$. Furthermore, 

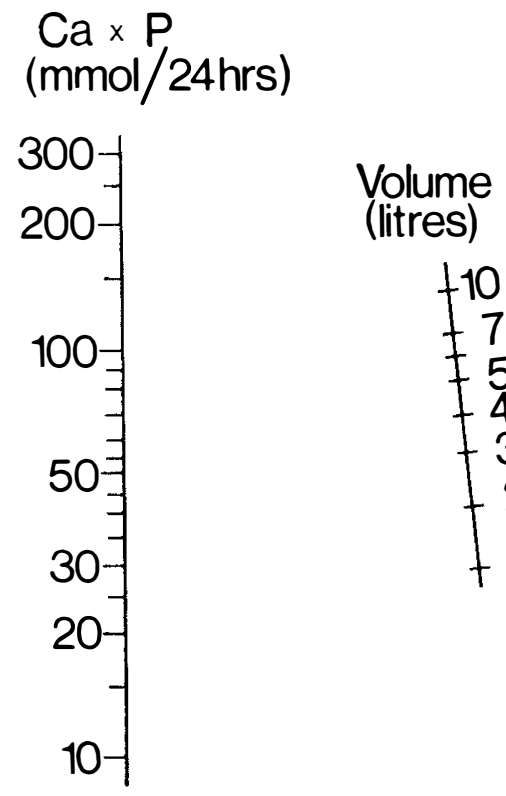

\section{$\mathrm{pH}$}

(litres)

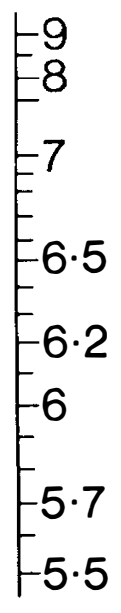

FIG. 2

Nomogram for $24-\mathrm{hr}$ volume of urine required to keep brushite in solution.

\section{Brushite}

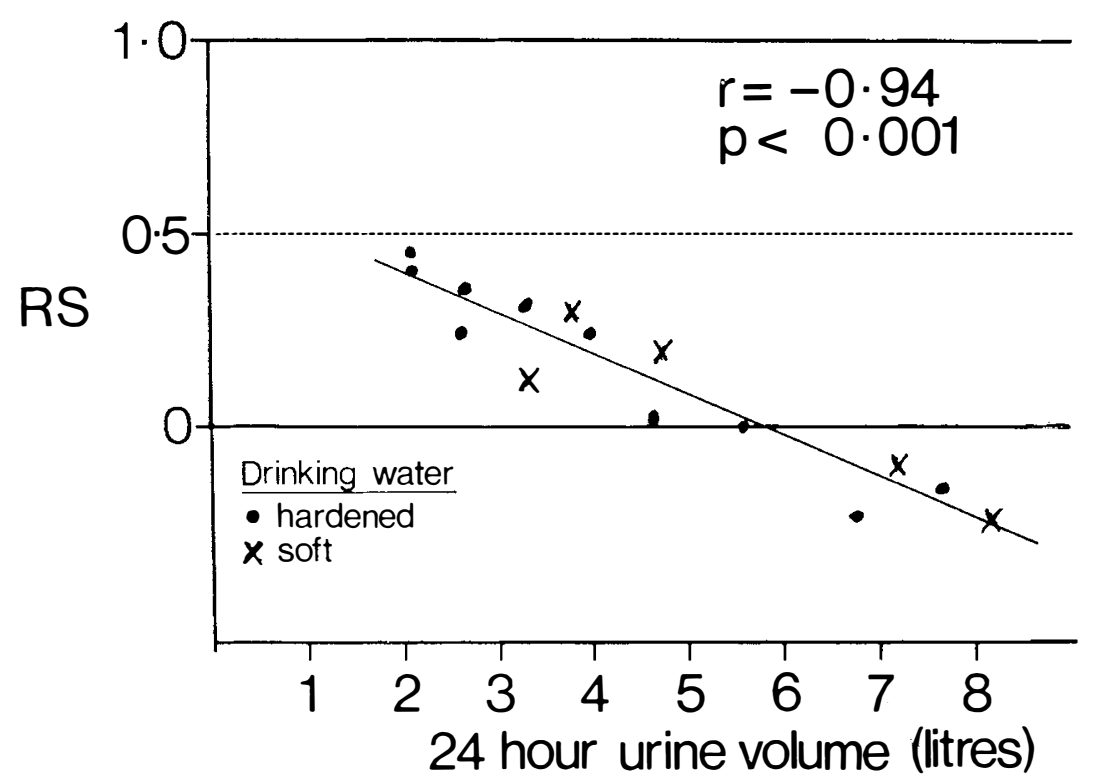

FIG. 3

Results for a male paraplegic with renal calculus. Regression of RS on volume for brushite.

The effect of drinking hard water is compared with that of drinking softened water. 


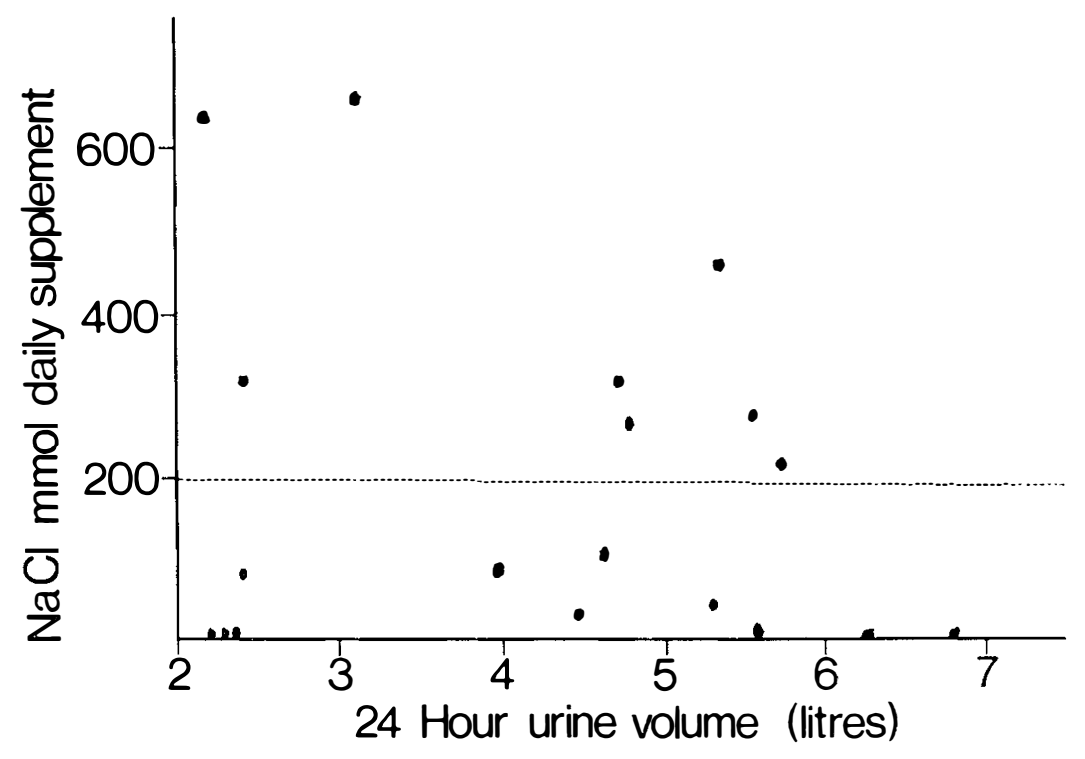

FIG. 4

Calculated dietary supplement of sodium chloride necessary to bring octocalcium phosphate into solution. Female paraplegic. No history of stone disease.

there is the possibility that $\mathrm{P}$ depletion may result from long-continued or excessive administration of the gel. Similarly, the long-term results of cellulose phosphate therapy, useful in treating the Ca-oxalate stone, are unknown in the paraplegic patient.

The nomograms of Marshall and Robertson (1976) provide a simple means of assessing the state of saturation of a sample of urine. The correction for ionic strength changes, applied in this study, resulted in a small difference in the results obtained, but was probably appropriate in view of the wide range of urinary concentrations encountered.

Urine from a healthy individual is frequently over-saturated with calcium phosphate, as observed in the two control subjects studied here. The fact that stone formation does not occur is attributed to the absence of a nidus and to the presence in the urine of inhibitors of crystal formation and/or aggregation. In the paraplegic patient the frequency and degree of over-saturation may be greater than in a non-paraplegic person due to increased alkalinity of the urine. There may also be a nidus present in the urinary tract and the normally occurring crystal growth inhibitors may be destroyed by the action of bacteria. If the urine could be kept under-saturated at all times, the formation and growth of crystals and, therefore, of calculi, in the urinary tract should be prevented.

The possibility of increasing fluid intake, and thus urinary dilution, to the point at which the urine becomes under-saturated is demonstrated by the results obtained from the two control subjects and ten of the patients (Fig. I and Table I). The volume required, however, varied in different individuals. The urinary output in one patient was less than 2 litres $/ 24 \mathrm{hr}$ but the majority of them showed the need for over 4 litres $/ 24 \mathrm{hr}$ to achieve under-saturation.

The nomogram (Fig. 2) provides a simple way of determining the volume 
per 24 hours required from a knowledge of calcium and phosphate excretion and $\mathrm{pH}$. The urinary calcium and inorganic phosphate excretions are expressed in terms of $\mathrm{mmol} / 24 \mathrm{hr}$, and the mean 24 -hour urinary $\mathrm{pH}$ is obtained from samples collected using a sufficient quantity of an efficient preservative, such as hibitane. A straight line is then drawn from the $\mathrm{Ca} \times \mathrm{P}$ product to the $\mathrm{pH}$. The volume is read from the point at which this line crosses the volume axis.

In our experience, it is not practical to expect the patient to produce more than 4 litres $/ 24 \mathrm{hr}$ of urine. When a larger volume is indicated it is, therefore, essential to attempt to reduce the $\mathrm{pH}$ by treating urinary infection whenever possible with the necessary antibiotics, by administering acidifying drugs, such as ascorbic acid, and to undertake some dietary measures such as the elimination or drastic reduction of milk and cheese and to increase $\mathrm{NaCl}$ consumption (Modlin I967).

There was no evidence of any benefit to be derived from drinking softened water (total hardness less than $15 \mathrm{mg} /$ litre) instead of the relatively hard Aylesbury tap water (total hardness averages $267 \mathrm{mg}$ /litre). In five patients, the ingestion of softened water produced a significant fall in the $\mathrm{Ca} \times \mathrm{P}$ product when the 24 -hour volume was over 4 litres, but $\mathrm{pH}$ variation was such that the effect was not significant when the RS values were compared. It is possible that the effect of soft water was too small to be detected in such a short experiment and that a longer study might have produced a measurable effect.

An alternative possibility is that any beneficial property that soft water may possess for the stone-forming patient resides in some constituent not measured in this study. Certain trace elements, for example, may modify the actions of crystal growth inhibitors (Thomas, 1969). Moreover the composition of soft water will vary between different sources and will differ from that obtained from a water softener. Reports in the literature regarding the value of soft or distilled water relate to other types of urinary stone and cannot directly be applied to the spinal cord patient.

\section{Conclusion}

Diuresis through increased fluid intake should be maintained. It is an important factor in preventing the formation and sometimes of bringing about the dissolution of urinary stones. The degree of diuresis $/ 24 \mathrm{hr}$ can be calculated. This should be undertaken in addition to energetic attempts to lower the urine $\mathrm{pH}$ and other dietary measures mentioned.

\section{RÉSUMÉ}

Une diurèse par prise d'eau doit être maintenue; un facteur important pour empêcher la formation et parfois pour aider la dissolution des calcules urinaires.

Le degré de diurèse doit être calculé en addition aux efforts énergique pour baisser le $\mathrm{PH}$ de l'urine et aux efforts de régime mentionnés.

\section{ZUSAMMENFASSUNG}

Bei der Behandlung von Nierensteinkrankheiten in querschnittsgelahmten Patienten schlagen wir vor, dass die Diurese durch erhöte Einnahme von Flüssigkeit erhalten bleibt. Das ist ein wichtiger Faktor zur Verhinderung der Steinformation. Manchmal kann sogar eine Avflösung der Nierensteine erfolgen. Der erwünschte Grad der Diurese pro 24 Stunden kann ausgerechnet werden. Zusätzlich zu versuchen ist den urin ph zu erniedrigen und andere erwähnte Diätmassnahmen auszuführen. 
Acknowledgements. We thank Dr A. Barr for the statistical analyses, Dr L. C. A. Nunn for the sodium and potassium determinations, Pamela Smith for technical assistance and Sylvia Nicol for secretarial help.

\section{REFERENCES}

Bates, R. G., Staples, B. R. \& Robinson, R. A. (I970). Ionic hydration and single ion activities in unassociated chlorides at high ionic strengths. Analyt. Chem., 42, 867-87I.

BuRR, R. G. (I978). Urinary calculi composition in patients with spinal cord lesions. Arch. Phys. Med. Rehabil., 59, 84-87.

Clark, P. B. \& Nordin, B. E. C. (1969). The problem of the calcium stone. Proc. Renal Stone Res. Symposium, Leeds I968, A. Hodgkinson \& B. E. C. Nordin (eds.), pp. I-5. Churchill, London.

Conway, B. E. (1952). Electrochemical Data, p. I02. Elsevier, New York.

Finlayson, B. (I974). Renal lithiasis in review. Urol. Clin. N. Amer., I, I8I-2I2.

KoHN, R. \& FURDA, I. (I967). Calcium ion activity in solutions of calcium pectinate. Collect. Czech. Chem. Commun., 32, I925-1937.

MARshall, R. W. \& Robertson, W. G. (I976). Nomograms for the estimation of the saturation of urine with calcium oxalate, calcium phosphate, magnesium ammonium phosphate, uric acid, sodium acid urate, ammonium acid urate and cystine. Clin. Chim. Acta, 72, 253-260.

Modis, M. (1967). The aetiology of renal stone: a new concept arising from studies on a stone-free population. Ann. Roy. Coll. Surg. Eng., 40, I55-I78.

Thомаs, W. C., Jr. (I969). Inhibitors of mineralisation and renal stones. Proc. Renal Stone Res. Symposium, Leeds I968, A. Hodginson \& B. E. C. Nordin (eds.), pp. I4II5I. Churchill, London.

Thomas, W. C., JR. (I974). Medical aspects of renal calculous disease. Urol. Clin. $N$. Amer., I, 26I-278.

Wade, A. (I977). Martindale: The Extra Pharmacopoeia, 27th ed., p. I447. The Pharmaceutical Press, London. 